\title{
Factors Affecting Foreign Tourist's Word-Of-Mouth toward Ho Chi Minh City-A Mediation Analysis of Destination Image
}

\author{
Mai Ngoc Khuong and Nguyen Truong Minh Bao
}

\begin{abstract}
This paper aimed to identify key factors affecting foreign tourists' word-of-Mouth as well as destination image of Ho Chi Minh City destination. Through path analysis, the study determined factors with significant direct and indirect effects toward tourists' word-of-mouth. These factors included culture, history and art; local cuisine; recreation and entertainment; safety and security; natural environment; negative attributes; infrastructure; and perceived price. Quantitative approach was majorly used, with statistical techniques applied including factor, multiple regression, and path analyses. Result of the research showed that all of eight factors had significant impact on Tourists' Word-of-Mouth, in which Recreation and Entertainment had the strongest effect. There was also significant relationship between destination image and foreign tourists' word-of-mouth. Through its finding and recommendations from tourists and tour guides, the research provided practical suggestions to improve Ho Chi Minh City's tourism industry.
\end{abstract}

Index Terms-Tourists' Word-of-Mouth, Ho Chi Minh City, destination image, path analyses.

\section{INTRODUCTION}

With over 3,200 km of coast line and geography in which $3 / 4$ is mountain area [1], Vietnam has full natural ability and geographical diversity to become a world destination for tourism. Together with Indonesia, Vietnam has the most World Heritage Sites among Asean nations (8 Sites) [2], both cultural and natural ones. However, according to Asean Tourism Statistics [3], Vietnam only had around 7,800,000 foreign tourists, placed $6^{\text {th }}$ over 10 countries in Asean. At the same time, as Malaysia topped the amount of foreigner visiting its country with $27,000,000$ arrivals in 2014 , it only owns 4 World Heritage Sites, equally half of Vietnamese amount. From 2010 to 2014, while Thailand increased its foreign arrivals from $15,000,000$ to $24,000,000$, Vietnam's development was only 2,800,000. From all the favor of nature and long lasting history of culture, Vietnam has the outstanding advantages to invest in the smokeless industry and attract people from all over the world. Although there is still plenty of room for development of tourism industry in Vietnam, the statistics presented a different result. Throughout recent years, Vietnam development has been

Manuscript received October 31, 2016; revised February 10, 2017

Mai Ngoc Khuong (PhD.) and Nguyen Truong Minh Bao (BA.) are with the School of Business, International University - VNU-HCM, Vietnam (e-mail: mnkhuong@hcmiu.edu.vn,ntmbao2111@gmail.com).

This research was supported by Department of Science and Technology and Department of Tourism-Ho Chi Minh City, Vietnam. falling gradually. Since 2010, the rate of development fell from $34.8 \%$ in 2010 to $19.1 \%$ in $2011,13.9 \%$ in $2012,1.6 \%$ in $2013,4 \%$ in 2014 before hit the bottom of .9\% in 2015 [4]. The government of Vietnam also noticed the trend and started to act to reverse the situation. In "Project of Strategic Development of Vietnam Tourism Product, up to 2025 and heading for 2030" signed in 2016 [5], the government aims to create a system of tourism products with high quality, sustainability and competency. The project also stated that the tourism industry and product must aim for harmonious relationships of ecotourism, culture, nature and unique characteristics of each destination.

As Ho Chi Minh City is one of the most popular destination of Vietnam, accounting for around $57.9 \%$ of total foreign tourist (2015) [6], this study tries to identify the elements that significantly relate to the Ho Chi Minh City's Destination Image and Word-of-Mouth, and the level of these relationships through path analysis. Finally, from empirical evidence and relationships between factors, the research can help tourism administrators and tourism stakeholders have a better understanding of tourists' experience and develop the best strategy to attract more arrivals.

\section{LITERATURE}

\section{A. Tourists' Word-of-Mouth}

In term of traditional marketing, loyalty can be measured by repeated sales or recommendation to other consumers [7], in which travel destination can also be included and be recommended to friends and family who are potential tourists [8].

For the definition of Word-of-Mouth (WOM), Ref. [9] stated it as post-purchase context consists of informal communications directed at other consumers about the ownership, usage, or characteristics of particular goods and services and/or their sellers. Ref. [10] stated "Word of mouth refers to information communications between private parties concerning evaluations of goods and services.

For more specification, Word of mouth (WOM) is the process of conveying information from person to person and plays a major role in customer buying decisions [11]. In commercial situations, WOM involves consumers sharing attitudes, opinions, or reactions about businesses, products, or services with other people [12]. Positive WOM is considered a powerful marketing medium for companies to influence consumers. WOM communication bases on social networking and trust: people rely on their families, friends and others in 
their social network. However, when it comes to opinions from outside of their immediate social network, people tend to disinterest, such as online reviews [13].

Word-of-Mouth is probably the oldest means of exchanging opinions on various goods and services offered by markets. As early as 1955, Ref. [14] believed that WOM was seven times more effective than direct sales, and twice as good as radio advertising. Few years after, Ref. [15] claimed that WOM is nine times more effective in changing customer's attitude than advertisement while Ref [16] showed that "other people recommendations" were three times better in term of stimulating purchases of over 60 different products than advertising.

WOM communications can occur face to face, by phone, email, mailing list, or any other means of communication [17]. Moreover, personal and impersonal sources of recommendations can also be considered. For personal source, they can be friends, family and acquaintances [18], [19]. On the other hand, expert systems and discussion forums are included as impersonal recommendation sources as consumers are influenced in their choice of products online by recommendations posted online [20], [21].

\section{B. Factors Affecting Tourists' Word-of-Mouth}

According to [22]-[26], Destination Image is an essential factor for tourist place and better image of the destination brings more tourist towards the places and give competitive advantage from competitors. Positive destination image place an important role to choose the tourist destination and enhance chance to visit any favorite destination place. Previous studies [27], [28] showed that destination image influences tourists in making destination, evaluation of the trip and their future intensions, and confirmed the positive relation between good destination image and higher chance of revisiting or recommending the destination to the others [29]-[32].

According to [33], destination image is viewed as "impressions that a person or persons hold about a state in which they do not reside". Ref [34] had his perception about this definition as: "our own personalized, internalized and conceptualized understanding of what we know" while Ref [35] simply stated destination image as an individual's overall perception or the total set of impressions of a place. It is also regarded as the mental portrayal of a destination [36].

Travel motivation is influenced by two forces - the concepts of Push and Pull factors [37], [38]. According to [39], Pull factors are recognized as the tangible resources and traveler's perception and expectation towards the features, attractions, or attributes of a specific destination. Pull factor is the external forces related to natural and historic attractions, food, people, recreation, facilities, and marketed image of the destination [40]. Ref. [41] showed in his study empirical evidences that attributes satisfaction had positive and direct causal effect to destination loyalty. Attributes included natural environment, culture, history and art, infrastructure, safety, price, leisure and recreation. In 2001, Ref. [42] with a research about relationship between preferences to destination and willingness to recommend to that destination; also gave evidences of the direct effects of cultural experience, safety, and convenient transportation on destination loyalty.
Ref. [43] defined culture as the ideas, customs, and the social behavior of a particular people or society. In tourism, Ref. [44] stated the quality of life, language barriers, hospitality and friendliness of the local residents, festival or concert, religion, historic attractions, customs and ways of life, political and economic factors to be cultural resource. Meanwhile, Ref. [45] claimed that one of the aspects increasing tourists' attention is the motivation of visitors to attend special event.

According to [46], food has become an increasingly significant element in the tourism industry an up to $25 \%$ of total tourism expenditure is accounted by foods or even higher. As Ref. [47] stated that food has been as not only a basic necessity for tourists' consumption but also a critical element of regional culture. Ref. [48] also confirmed that by putting more effort in local cuisine, tourists will have more opportunities to be in a more memorable and enjoyable holiday atmosphere than they expected and improvement in food service also enhances customer satisfaction.

Perceived cost is the price what customers actually pay in exchange for the benefits accruing from a product or service [49]. Price influences the buyers' expectation at service level. A too low price suggests inferior quality [50] and indicates too high risk. Customers are willing to pay more for a service to decrease the uncertainty [51] and prices can be seen as "a visible of a service's level and quality and a mean of reducing perceived risk" [52]-[53].

In the literature there are some differences between "safety" and "security". Ref. [54] defined "safety is protection against random incidents, which are unwanted incidents that happen as a result of one or more coincidences. On the other hand, "security" is protection against intended incidents, which are unwanted incidents happen due to a result of deliberate and planned acts. The idea behind both terms is to take care of people by eliminating any hazards and threats and ensuring a safe and secure environment. The difference between them is that safety is concerned about protecting human lives and health while security is more about protection against criminal activities [55].

According to [43], infrastructure is defined as the basic physical and organizational structure and facilities (e.g. roads, buildings, power supplies, etc.) needed for the operation for the society or enterprise. Infrastructure includes general infrastructure (transport facilities, health care, telecommunication, etc.) and tourist infrastructure (accommodation, hotels, restaurants, tourist centers, etc.) [44]

Ref. [44] also mentioned natural environment includes all things existing in nature and are not made or caused by human. In tourism field, natural environment comprises many factors such as weather, beach, lake, river, mountain..... Natural environment has always played an important role and is seen as a main source to tourism sector [56]. Moreover, Ref. [57] showed that the satisfaction level of tourists has dependence on the natural ambiance and climate condition of the geographical location.

Ref. [43] defined entertainment as films/movies, music, etc. used to entertain people while recreation is the particular activity that people do when they are not working. Ref [44] stated that leisure and entertainment includes outdoor activities, adventure activities, shopping as well as nightlife, 
etc. Entertainment opportunities are among important attractions with theatre, concerts, bars, restaurants, discos, etc. [58]

Ref. [59] defined negative attributes through the opposition to the positive attributes, as the positive attributes are characteristics that convey favorable impressions about the destination. Both positive as well as negative destination attributes are important in evaluating the holiday experiences as tourist's overall satisfaction is significantly conditional upon their satisfaction with the destination attributes [8]. Ref. [60] also confirmed about the effect of negative attributes on the holiday satisfaction.

\section{The Proposed Hypotheses}

In order to obtain all the objectives and further analyses, this study hypothesizes that:

$\mathrm{H}_{1}$ : Factors of local cuisine; culture, history and art; perceived price; infrastructure; natural environment; entertainment and recreation; safety and security; and negative attributes directly affect destination images.

$\mathrm{H}_{2}$ : Factors of local cuisine; culture, history and art; perceived price; infrastructure; natural environment; entertainment and recreation; safety and security; negative attributes; and destination image directly affect tourists' word-of-mouth.

$\mathrm{H}_{4}$ : Tourists' word-of-mouth is indirectly affected by factors of local cuisine; culture, history and art; perceived price; infrastructure; natural environment; entertainment and recreation; safety and security; negative attributes through destination image.

\section{Methodology}

\section{A. Questionnaire Design and Data Collection}

The purpose of this research was to determine which factor affect foreign tourists' word-of-mouth about Ho Chi Minh City destination. Quantitative approach was applied with structured questionnaires conveniently and directly delivered to 1,673 international tourists who were staying at least 2 days in Ho Chi Minh City. Most of the measured items in the questionnaire used 5-point Likert scale which ranges from 1 as "strongly disagree" and 5 as "strongly agree".

\section{B. Factor Analysis and Reliability}

To test the validity of the scales, two exploratory factor analyses were conducted for dependent variables and independent variables. There were two dependent variables with eight measured items while the group of eight independent variables included 38 measured items. As the result, the Kaiser-Meyer-Olkin (KMO) measure of sampling adequacy was .816 for the group of dependent variables and .907 for the group of independent variables.

TABLE I: SUMMARY OF DEPENDENT VARIABLES

\begin{tabular}{lcc}
\hline \hline Given name & Number of items & Alpha \\
\hline Destination Image (DESIMAGE) & 05 & .759 \\
Word-of-Mouth (WOM) & 03 & .814 \\
\hline \hline
\end{tabular}

Based on Kaiser-Guttman's retention criterion of
Eigenvalue greater than 1, two dependent variables together with eight items were considered appropriate to maintain for further analysis. These factors accumulated for 59.524 percent the total variance explanation and Cronbach's coefficients ranged from .759 to .814 , which also indicated good subscale reliability.

TABLE II: SUMMARY OF INDEPENDENT VARIABLES

\begin{tabular}{lcc}
\hline \hline Given names & $\begin{array}{c}\text { Number } \\
\text { of items }\end{array}$ & Alpha \\
\hline Negative Attributes (NEGAT) & 07 & .778 \\
Culture, History and Art (CULHISART) & 04 & .824 \\
Safety and Security (SAFSEC) & 05 & .761 \\
Perceived Price (PERPRICE) & 05 & .801 \\
Infrastructure (INFRAS) & 04 & .768 \\
Natural Environment (NATENVI) & 05 & .774 \\
Local Cuisine (LOCUIS) & 04 & .806 \\
Entertainment and Recreation (RECENTER) & 04 & .703 \\
\hline \hline
\end{tabular}

For independent variables, same method was used and all eight variables with 38 items were retained as the result. These factors claimed for 57.543 percent of the total variance explanation. The Cronbach's coefficients varied from .703 to .824 , indicating good subscale reliability.

\section{RESEARCH FINDING}

\section{A. Profiles of Tourists Involved in Study}

Among 1,673 questionnaires collected, the male participants contributed with higher rates as $53.4 \%$ over $46.6 \%$ of female. The difference is quite small and the research still maintained qualified for representing the popularity of foreign tourists visiting Ho Chi Minh City.

The age of all participants was also spread widely among 6 groups, from under 18 years old to over 60 years old, confirmed that the research had strong representation quality for the total tourist popularity of Ho Chi Minh City. About age groups, the ratios among groups were quite equal as $25 \%$, $24.2 \% 23.1 \%$, and $18.5 \%$ respectively for groups of $18-25$, 26-30, 31-40 and 41-60 years old. The bell-shape distribution also showed diversity of tourists in Ho Chi Minh City but still focus on young and middle-age people. Moreover, most people came to Ho Chi Minh City to relax and look for leisure as the ratio for this group was up to $62.9 \%$.

For the level of education of tourists in Ho Chi Minh City, the profile presented quite high level of education as majority of participant was bachelor degree holders. The ratio was $14.9 \%, 38.7 \%$ and $21.1 \%$ respectively for people undergraduate, graduate and postgraduate. So the total percentage of people who are going to have or already achieved bachelor degree was $74.7 \%$, around $3 / 4$ of all the questionnaire answered, showing great potential for high-educated shows such as gallery, traditional arts or cultural, history and museums tours. The research also showed that $15 \%$ of arrivals were business, recommending development for MICE travel and hospitality.

In diversity of country of tourists, the most significant contributors were Asia and Europe with percentage, respectively $46.4 \%$ and $31.6 \%$. These two continents also made up for around $3 / 4$ of the survey. There were totally 6 areas all around the world included in the survey, which were 
Europe, America/ Canada, Latin America, Asia, Australia and New Zealand and Africa. This result pointed out the demand for diversify entertainment program and tours design to be specified and suitable for each source of tourists.

Finally is the amount of times visitors had come to Ho Chi Minh City. The survey presented a surprise result as $35.2 \%$ had visited this city for more than once. For more specific, $15.3 \%$ of visitors come to Ho Chi Minh twice, $7.3 \%$ of them had made the third times and $12.6 \%$ had returned for more than 3 times. $64.9 \%$ of the tourists visited Ho Chi Minh first time.

\section{B. Relationship between Destination Image, Tourists' Word-of-Mouth and Independent Variables}

In order to determine which factors whose relationships with dependent variables of tourists' Word-of-Mouth, the research applied Pearson Correlation (r). As below, the table IV showed the presence of positive correlations between dependent variables WOM and DESIMAGE $(r=.468, \mathrm{p}$ $<.001$ ), between WOM and independent variables: DESIMAGE $(\mathrm{r}=.468, \mathrm{p}<.001)$;CULHISART $(\mathrm{r}=.356, \mathrm{p}$ $<.001)$; SAFSEC $(\mathrm{r}=.330, \mathrm{p}<.001)$; PERPRICE $(\mathrm{r}=.456, \mathrm{p}$ $<.001)$; INFRAS $(\mathrm{r}=.415, \mathrm{p}<.001)$; NATENVI $(\mathrm{r}=.369, \mathrm{p}$ $<.001)$; LOCUIS $(r=.426, p<.001)$;RECENTER $(r=.443$, $\mathrm{p}<.001)$. These figure meant that if CULHISART, SAFSEC, PERPRICE, INFRAS, NATENVI, LOCUIS, RECENTER and DESIMAGE are improved; they can lead to better tourists' Word-of-Mouth.

TABLE IV: CORRELATIONS BETWEEN VARIABLES

\begin{tabular}{|c|c|c|c|c|c|c|c|c|c|}
\hline & WOM & 1 & 2 & 3 & 4 & 5 & 6 & 7 & 8 \\
\hline 1.NEGAT & $-.095^{*}$ & 1 & & & & & & & \\
\hline 2.CULHISART & $.356^{*}$ & -.022 & 1 & & & & & & \\
\hline 3.SAFSEC & $.330^{*}$ & -.025 & $.292^{*}$ & 1 & & & & & \\
\hline 4.PERPRICE & $.456^{*}$ & $-.069^{*}$ & $.410^{*}$ & $.353^{*}$ & 1 & & & & \\
\hline 5.INFRAS & $.415^{*}$ & $-.126^{*}$ & $.457^{*}$ & $.440^{*}$ & $.520^{*}$ & 1 & & & \\
\hline 6.NATENVI & $.369^{*}$ & $-.141^{*}$ & $.509^{*}$ & $.406^{*}$ & $.347^{*}$ & $.504^{*}$ & 1 & & \\
\hline 7.LOCUIS & $.426^{*}$ & $.041^{* *}$ & $.400^{*}$ & $.355^{*}$ & $.580^{*}$ & $.467^{*}$ & $.312^{*}$ & 1 & \\
\hline 8.RECENTER & $.443^{*}$ & $-.063^{*}$ & $.526^{*}$ & $.279^{*}$ & $.518^{*}$ & $.473^{*}$ & $.433^{*}$ & $.425^{*}$ & 1 \\
\hline 9.DESIMAGE & $.468^{*}$ & -.026 & $.476^{*}$ & $.295^{*}$ & $.540^{*}$ & $.506^{*}$ & $.332^{*}$ & $.525^{*}$ & $.516^{*}$ \\
\hline Mean & 3.94 & 3.63 & 3.60 & 3.52 & 3.82 & 3.61 & 3.38 & 4.07 & 3.52 \\
\hline SD & .765 & .682 & .717 & .713 & .666 & .698 & .743 & .659 & .666 \\
\hline
\end{tabular}

\section{Direct Effects on Tourists' Word-of-Mouth}

From multiple regression analysis, it could be concluded that six out of eight independent variables had a direct effect on tourists' word-of-mouth. They were PERPRICE (B = .141, $\mathrm{p}<.001)$, LOCUIS $(\mathrm{B}=.136, \mathrm{p}<.001)$, RECENTER $(\mathrm{B}$ $=.165, \mathrm{p}<.001), \operatorname{SAFSEC}(\mathrm{B}=.098, \mathrm{p}<.001), \operatorname{NEGAT}(\mathrm{B}=$ $-.063, \mathrm{p}<.05)$, NATENVI $(\mathrm{B}=.108, \mathrm{p}<.001)$. These figure also showed that for the positive effect, SAFSEC was the weakest of six factors while RECENTER came first on the list. It indicated that if tourists have an experience with perceived price, local cuisine, safety and security, and especially recreation and entertainment, they will improve their word-of-mouth. On the other hand, as negative attribute had negative effect on tourists' word-of-mouth, a reduction in this factor will also make tourists' word-of-mouth become better.

From the simple linear regression analysis between tourists' word-of-mouth and destination image, DESIMAGE had a positive effect on WOM $(\mathrm{B}=.231, \mathrm{p}<.001)$. The result confirmed that an increase in Destination Image will lead to an increase in tourists' word-of-mouth. The total direct effect of variables on WOM was .816 .

\section{Indirect Effect on Tourists' Word-of-Mouth}

According to [61], the independent variable's indirect effect on the dependent variable through mediating variable was the total product of independent variable's effect on the mediating variable and mediating variable's effect on the independent variable.

Based on the multiple regression analysis at level of significance of .05 , there were six over eight independent variables that had effect on the destination image. They were: CULHISART (B = .142), PERPRICE (B = .169), INFRAS (B $=.156)$, LOCUIS $(\mathrm{B}=.194)$ RECENTER $(\mathrm{B}=.169)$, and NATENVI $(\mathrm{B}=-.039)$. So it can be concluded that when tourists are satisfied with culture, history and art; perceived price; local cuisine; and recreation and entertainment, they are more likely to be satisfied with destination image of that place. On the other hand, as the natural environment had the negative $B$ value, it indicated that the tourists would likely have better word-of-mouth if the natural environment issues are minimized.

As these six factors had a direct effect on destination image and destination image also had a direct effect on tourists' word-of-mouth $(\mathrm{B}=.231)$, these factors had indirect effect on tourists' word-of-mouth through the mediation variable of DESIMAGE. The indirect effects were CULHISART (B $=.033)$, PERPRICE $(\mathrm{B}=.039)$, INFRAS $(\mathrm{B}=.036)$, LOCUIS (B = .045), RECENTER ( $\mathrm{B}=.039)$, and NATENVI $(\mathrm{B}=-.009)$. The total indirect effect of WOM was .183.

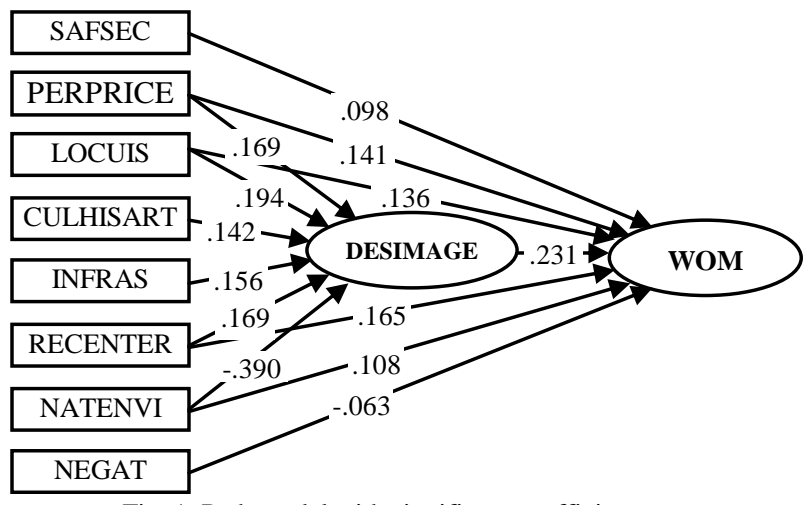

Fig. 1. Path model with significant coefficients.

\section{E. Significant of the Indirect Effect}

Based on the bootstrapping method recommended by [61] to test the significance of the indirect effect or mediation, table $\mathrm{V}$ showed the bootstrapped confidence intervals (at the $95 \%$ ). According them, in order for a mediation to be accept, there must be no ZERO (0) lies within the interval rang between the lower limit (LL) and the upper limit (UL). Because if there is ZERO (0) within the interval, at one point there will be no coefficient, which means that there is no mediation or indirect effect. On the other hand, if the interval is free from ZERO (0), it can be concluded that, with $95 \%$ confidence, the mediation or indirect effect is significant [62]. So as the results showed in table V, the indirect effects of CULHISART, PERPRICE, INFRAS, LOCUIS, RECENTER and NATENVI through the mediation of DESIMAGE on WOM were estimated to lie between .0226 and $.0445 ; .0267$ and $.0519 ; .0246$ and $.0487 ; .0320$ and $.0587 ; .0271$ and .0523 ; - .0172 and - .0016 with $95 \%$ confidence, 
respectively. Because there was no zero within these intervals, the research can come to conclusion that the indirect effects of CULHISART, PERPRICE, INFRAS, LOCUIS, RECENTER, and NATENVI were indeed significantly different from zero at $\mathrm{p}<.05$ (two tailed) and the mediation of DESIMAGE in this study is confirmed.

\section{F. Total Causal Effect of Tourists' Word-of-Mouth}

The total effect of one variable on WOM could be classified into direct and indirect effect. The table V shows the effects independent variables including CULHISART, PERPRICE, INFRAS, LOCUIS, RECENTER, SAFSEC, NEGAT, NATENVI and DESIMAGE on WOM.

According to the resulted presented in the table, DESIMAGE had the strongest effect on WOM with $\mathrm{B}=.231$ which according to [63] is moderate effect. Following up is the RECENTER with another moderate effect on WOM as owing the $\mathrm{B}=.204$. The factors of LOCUIS, PERPRICE, NATENVI, SAFSEC, INFRAS and CULHISART also had considerable and positive effects on WOM with coefficient values respectively were $.181, .180, .099, .098, .036$ and .033 . Meanwhile, the last factor of NEGAT was found to have a negative effect on WOM with $\mathrm{B}=-.063$. The total effect of all these nine factors on WOM was .999.

TABLE V: DIRECT, INDIRECT AND TOTAL EFFECTS

\begin{tabular}{lccccc}
\hline \hline \multirow{2}{*}{ Variables } & \multicolumn{3}{c}{ Causal effects } & & \\
\cline { 2 - 4 } CULHISART & Direct & Indirect & Total & LL & UL \\
\hline PERPRICE & ---- & .033 & .033 & .0226 & .0445 \\
INFRAS & .141 & .039 & .180 & .0267 & .0519 \\
LOCUIS & ---- & .036 & .036 & .0246 & .0487 \\
RECENTER & .136 & .045 & .181 & .0320 & .0587 \\
NATENVI & .165 & .039 & .204 & .0271 & .0523 \\
SAFSEC & .108 & -.009 & .099 & -.0172 & -.0016 \\
NEGAT & .098 & ---- & .098 & & \\
DESIMAGE & -.063 & ---- & -.063 & & \\
\hline \multicolumn{1}{c}{ Total } & .231 & ---- & .231 & & \\
\hline \hline
\end{tabular}

\section{DISCUSSION AND RECOMMENDATION}

\section{A. Discussion of Finding}

According to table $\mathrm{V}$, destination image was the factor owning the most powerful effect on tourists' word-of-mouth. Next is the recreation and entertainment factor, followed by local cuisine, perceived price, natural environment, safety and security and culture, history and art. These factors are listed as their positive $B$ values descend, representing for positive significant effect on tourists' word-of-mouth. The result is consistent with many antecedent studies such as [30], [41], [64]-[66]. On the other hand, negative attributes are also proven to have negative significant effect on tourists' word-of-mouth with negative $B$ value.

Based on the degree of effects of these factors above, it could be concluded that destination image was the strongest factor that affected significantly to tourists' word-of-mouth, followed by local cuisine, perceived price, natural environment, safety and security, negative attributes and finally culture, history and art.

\section{B. Recommendation for Tourism Decision Makers in Ho Chi Minh City}

For the recreation and entertainment, Ho Chi Minh City still lacks of place to play at night. Although there is an increasing in the number of bars, pub and night clubs in the city, they mostly locate in city center and the service are nearly the same. The coffee shop with acoustic music or traditional music could be a unique point of attraction of the city. The open of the Food Street, Book Street and walking street in the central of the city is also a good solution to create entertainment for the guests. Moreover with the advantage of nearby green and signature area such as $\mathrm{Cu} \mathrm{Chi}$, Dong Nai Province or Can Gio Botanical Preserve Forest, the tourism maker can consider investing in eco-tourism to help the tourists to discover another point of view of the city with significant cultural characteristics of Mekong Delta right in city.

Secondly, although the cuisine of Vietnam has already been quite well-known in the world, city needs shows for guests to enjoy all types of food at once. Food festival or cooking contest can be organized regularly in other to foreigner to witness and taste all the famous dishes of Vietnam. Reality shows such as "Master Chef" or "Gordon's Great Escape" has already come to Vietnam, these are great chance to use Local Cuisine to attract people from all over the world. As convenient as founding most of traditional dishes easily in small food stall on the street, the hygiene and quality of the food need more governance in order to enhance good experience for tourists.

And for the most important factor, the destination image, the research showed that it had significant relationships with all 8 independent factors, in which top 3 strongest bonds are RECENTER, LOCUIS, and PERPRICE. So the improvement of destination image must come from improvement of all 8 independent factors and most importantly, from RECENTER, LOCUIS, and PERPRICE. As recommendations for RECENTER and LOCUIS has already been mentioned, there are few things the administrators can do to better off the perceived price. Although there are not many cases of price discriminations or cheating in Ho Chi Minh City, cases happened in Vung Tau or other cities still created bad impressions for tourists for Vietnam in general and Ho Chi Minh City in specific. This is a very sensitive aspect and a hotline for emergency report will be great first step to gain back trust from both foreigner and residences. A lower cost of living can be an attractive point for backpackers who searching for street and deep engaging in society style of travel, which leads to measures to fight against inflation.

With culture, history and art, there are many traditional arts gaining interesting from foreigner customers. However, most of them are in recession and need serious conservative actions to build up descendant force to continue to maintain and expand the traditional and cultural art of Vietnam. More free performances in public places or well prepared shows means more chance for people to discover the hidden beauty of these arts and performers also has better income in life. Moreover, popular destinations in Ho Chi Minh City are usually in short of introduction for travelers to understand. Small panels with summary of these places and recommendation for nearby destinations can help the arrivals engage deeper in discovery the culture and history of the city, bringing much more excitement in their journey. Specifically for 10 museums all over the city, Virtual Reality (VR) and many other modern 
technologies can help customers get more interactions and walk themselves through the heroic wars of Vietnamese majestic history of protecting freedom.

With safety and security factor, street safety should be put in first place. Tourists must be protected from thief and robbery. Hotline for emergency report and quick respond team are first steps to keep them safe from threat. Moreover, as much security cameras be installed and police guarding in popular destinations as possible will also decrease the rate of crimes in society.

Finally is the infrastructure factor. One of the most critical recommendations from tour guide and tourists is to improve the public facility, or more specifically the bus system, restroom and trash can. The city seriously lacks of trash bin and restroom and the current ones in use are usually overload. For bus system, the communication skills for employees also need to develop as most bus drivers are unable to speak English. Guiding panels need to have English subtitle to guide foreigner, too. Another dimension that receives many requirements to improve from the research is fresh air or interior decoration. For the airport and famous destinations, they are in short of green area as tourists often find themselves stuck in concrete and wall. Suggestion to follow the Changi International Airport of Singapore with butterfly garden or meditation chamber for Buddhist or Islam should be considered.

\section{Limitations of the Study and Future Research}

First of all, the research is limited with convenient sampling method. Due to the restriction of time, finance, location and human resource, the researcher could only deliver surveys to tourists in popular destinations Ho Chi Minh City. Therefore, the result of the study could not represent all tourists' opinions about this city.

It is recommended that further study should invest more time and effect to build a more comprehensive research model and conduct research with more suitable method, which makes the result more accurate. Lastly, the research's conceptual framework was lack of some constructs, such as perceived value [66]-[68]; perceive service quality [67], [68]. For that reason, future research can consider about supplementing these factors in the model. Moreover, the negative direct effect on destination image, which led to negative indirect effect on word-of-mouth should also be further investigated and checked. NATENVI alone still had proven positive significant correlation on the DESIMAGE and WOM.

\section{CONCLUSION}

All the research targets of this study have been achieved. Not only did it identify factors whose significant relations with Word-of-Mouth and Destination Image, but it also measured the direct effects to main dependent variable, and indirect effect through mediation variable. Together with previous theoretical studies and empirical evidences, the research helped to give practical recommendations to improve foreign tourists' Word-of-Mouth.

For further studies, researchers should consider to expand the model with many other important factors such as perceived value, perceived quality or government policies in order to achieve better explanation of Word-of-Mouth. Other dependent factors such as Tourist's Loyalty or Tourist's Return Intention should also be studied to have deeper understanding about the field of hospitality management.

\section{REFERENCES}

[1] Vietnam Geographical Information, Vietnam Government Information Port.

[2] World Heritage List Statistic, UNESCO, 2015.

[3] Tourist Arrivals in ASEAN, ASEAN Tourism Statistics Database, 2015 .

[4] Vietnam Tourism Development Report 2015, Vietnam Tourism Association.

[5] Project of Strategic Development of Vietnam Tourism Product, up to 2025 and heading for 2030, Vietnam Tourism Department, 2016

[6] International Visitors to Vietnam in December 2015 and 12 Months of 2015, Vietnam General Statistics Office, 2015.

[7] P. D. Peppers and M. Rogers, "Do you want to keep your customers forever?" Harvard Business Review, pp. 103-114, 1995.

[8] Y. Yoon and M. Uysal, "An examination of the effects of motivation and satisfaction on destination loyalty: A structural model," Tourism Management, vol. 26, pp. 45-56, 2005.

[9] R. A. Westbrook, "Product/consumption-based affective responses and postpurchase processes," Journal of Marketing Research, vol. 24, no. 3, pp. 258-270, 1987.

[10] E. W. Anderson, "Customer satisfaction and word-of-mouth,” Journal of Service Research, vol. 1, no. 1, pp. 5-17, 1998.

[11] M. L. Richins and T. Root-Shaffer, "The role of involvement and opinion leadership in consumer word-of-mouth: An implicit model made explicit," Advances in Consumer Research, vol. 15, pp. 32-36, 1988.

[12] B. J. Jansen, M. Zhang, K. Sobel, and A. Chowdury, "Twitter power: Tweets as electronic word of mouth," Journal of the American society for information science and technology, vol. 60, no. 11, pp. 2169-2188, 2009.

[13] W. Duana, B. Gub, and A. B. Whinston, "Do online reviews matter?-An empirical investigation of panel data," Decision Support Systems, vol. 45, no. 3, pp. 1007-1016, 2008.

[14] E. Katz and P. F. Lazarsfeld, "Personal influence," Glencoe, IL: Free Press, 1955.

[15] G. S. Day, "Attitude change, media, and word of mouth," Journal of Advertising Research, vol. 11, no. 6, pp. 31-40, 1971.

[16] S. P. Morin, "Influentials advising their friends to sell lots of high-tech gadgetry," Wall Street Journal, February 28, 30, 1983.

[17] D. F. Duhan, S. D. Johnson, J. B. Wilcox, and G. D. Harrell, "Influences on consumer use of Word-of-Mouth recommendation sources," Journal of the Academy of Marketing Science, vol. 25, no. 4, pp. 283-295, 1997.

[18] G. Silverman, The Secrets of Word-of-Mouth Marketing, New York: American Management Association, 2001.

[19] J. J. Brown and P. H. Reingen, "Social ties and word-of-mouth referral behavior," Journal of Consumer research, pp. 350-362, 1987.

[20] S. Sénécal and J. Nantel, "The Influence of online product recommendations on consumer's online choices," Journal of Retailing, vol. 80, no. 2, pp. 159-169, 2004.

[21] S. Sénécal, P. J. Kalczynski, and J. Nantel, “Consumers' decision making process and their online shopping behavior: A clickstream analysis". Journal of Business Research, vol. 58, pp. 1599-1608, 2005.

[22] C. H. C. Hsu, K. Wolfe, and S. K. Kang, "Image assessment for a destination with limited comparative advantages," Tourism Management, vol. 25, pp. 121-126, 2004.

[23] R. J. Mykletun, J. C. Crofts, and A. Mykletun, "Positioning an island destination in the peripheral area of the Baltics: A flexible approach to market segmentation," Tourism Management, vol. 22, no. 5, pp. 493-500, 2001.

[24] Y. Fan, "Branding the nation: What is being branded?" Journal of Vacation Marketing, vol. 12, no. 1, pp. 5-14, 2006.

[25] J. T. Coshall, "Measurement of tourists' images: The repertory grid approach," Journal of Travel Research, vol. 1, pp. 85-89, 2000.

[26] S. O'Leary and J. Deegan, "Ireland's image as a tourism destination in France: attribute importance and performance," Journal of Travel Research, vol. 43, pp. 247-56, 2005.

[27] S. Baloglu and K. McCleary, "A model of destination image formation," Annals of Tourism Research, vol. 26, no. 4, pp. 868-897, 1999. 
[28] K. S. Chon, "The role of destination image in tourism: A review and discussion," Tourist Review, vol. 45, no. 2, pp. 2-9, 1990.

[29] L. H. Lobato, M. M. Solis-Radilla, M. A. Moliner-Tena, and J. Sa'nchez-Garci'a, "Tourism destination image, satisfaction and loyalty: A study in IxtapaZihuatanejo, Mexico," Tourism Geographies, vol. 8, no. 4, pp. 343-358, 2006.

[30] C. Chen and D. Tsai, "How destination image and evaluative factors affect behavioral intentions," Tourism Management, vol. 28, no. 4, pp. 1115-1122, 2007.

[31] G. Prayag, "Image, satisfaction and loyalty-The case of Cape Town. Anatolia," An International Journal of Tourism and Hospitality Research, vol. 19, no. 2, pp. 205-224, 2008.

[32] P. Woomi and J. Soocheong, "Destination image and tourist attitude," Tourism Analysis, vol. 13, no. 4, pp. 401-411, 2008.

[33] J. D. Hunt, "Image: A Factor in Tourism," Cited in N. Telisman-Kosuta (1989) (Tourism Destination Image), Tourism Marketing and Management Handbook, S. F, 1971.

[34] R. J. Markin, Consumer behavior; a cognitive orientation, Michigan University, Mac Millan, 1974.

[35] A. Phelps, "Holiday destination image-The problem of assessment: An example developed in Menorca," Tourism Management, vol. 7, no. 3, pp. 168-180, 1986.

[36] A. M. Alhemoud and E. G. Armstrong, "Image of Tourism Attractions in Kuwait," Journal of Travel Research, vol. 34, no. 76, 1996.

[37] M. S. Dann, "Anomie ego-enhancement and tourism," Annals of Tourism Research, vol. 4, no. 4, pp. 184-194, 1977.

[38] G. M. S. Dann, "Tourist motivation: An appraisal," Annals of Tourism Research, vol. 8, no. 2, pp. 187-219, 1981.

[39] J. L. Crompton, "Motivations for pleasure vacations," Annals of Tourism Research, vol. 6, no. 4, pp. 408-424. 1979.

[40] M. Uysal and L. Hagan, "Motivations for pleasure travel and tourism," Encyclopedia of Hospitality and Tourism, New York: Van Nostrand Reinhold, pp. 798-810, 1993.

[41] G. Chi, "A study of developing destination loyalty model," Ph.D Dissertation, Dept. Philosophy, Oklahoma State University, Stillwater, Oklahoma, U.S, 2005.

[42] J. S. Chen Dogan Gursoy, "An investigation of tourists' destination loyalty and preferences," International Journal of Contemporary Hospitality Management, vol. 13, no. 2, pp. 79-85, 2001.

[43] A. S. Hornby, Oxford Advanced Learner's Dictionary, 7th ed. Oxford University Press, US, March $3^{\text {rd }} 2005$.

[44] Beerli and J. D. Martin, "Factors influencing destination image," Annals of Tourism Research, vol. 31, no. 3, pp. 657-681, 2004.

[45] M. Uysal, G. Howard, and U. Jamrozy, "An application of importance-performance analysis to a Ski resort: A case study in North Carolina," Visions in Leisure and Business, vol. 10, no. 1, pp. 16-25, 1991.

[46] L. E. Hudman, "The travelers' perception of the role of food and eating in the tourist industry," in Proc. 36th AIEST Congress on The Impact of Catering and Cuisine upon Tourism, 31 August-6 September, 1986.

[47] A. Jones and I. Jenkins, "A taste of Wales-Blas Ar Gymru: Institutional malaise in promoting welsh food tourism products," Tourism and gastronomy, pp. 115-132, 2002.

[48] S. Quan and N. Wang, "Towards a structural model of the tourist experience: An illustration from food experiences in tourism," Tourism Management, vol. 25, no. 3, pp. 297-305, 2004.

[49] J. Wirtz, Patricia Chew and Christopher Lovelock, Essentials of Services Marketing, $2^{\text {nd }}$ ed. Singapore, Pearson Education South Asia Pte Ltd, 2007.

[50] V. A. Zeithaml, M. J. Bitner, and D. D. Gremler, Services Marketing. New York. McGraw Hill, 1996

[51] K. D. Hoffma and J. E. Bateson, Essentials of Service Marketing, Dryden Press, Fort Worth, TX, 1997.
[52] A. Parasuraman, L. L. Berry, and V. A. Zeithaml, "Refinement and reassessment of the SERVQUAL scale," Journal of retailing, vol. 67, no. 4 , pp. 420,1991

[53] C. Boshoff, "Service Advertising: An exploratory study of risk perceptions," Journal of Service Research, vol. 4, pp. 290-298, 2002

[54] E. S. Ids $\varnothing$ and $\varnothing$. M. Jakobsen, "Objekt- og informasjonssikkerhet. Metode for risiko og sårbarhetsanalyse. ROSS report 200027," Dept. Production and Quality Engineering, NTNU, 2000.

[55] E. Albrechtsen, "Security vs safety," NTNU - Norwegian University of Science and Technology, Dept. Industrial Economics and Technology Management, 2003.

[56] Inskeep and P. Pelancongan, Tourism Planning, 1st ed. Kuala Lumpur, Malaysia: Norlida Halim, pp. 30-38, 1996.

[57] S. Coban, "The effects of the image of destination on tourist satisfaction and loyalty: The case of cappadocia," European Journal of Social Sciences, vol. 29, no. 2, pp. 222-232, 2012.

[58] J. A. Mazanec, International City Tourism: Analysis and Strategy, Pinter, 1997

[59] T. Truong and D. Foster, "Using HOLSAT to evaluate tourist satisfaction at destination: The case of Australian holidaymakers in Vietnam," Tourism Management, pp. 842-855, 2006.

[60] Tribe and T. Snaith, "From SERVQUAL to HOLSAT: Holiday satisfaction in Varadero, Cuba," Tourism Management, vol. 19, pp 25-34, 1998

[61] K. Preacher and A. F. Hayes, "Asymptotic and resampling strategies for assessing and comparing indirect effects in multiple mediato models," Behavior Research Methods, vol. 40, no. 3, pp. 879-891, 2008.

[62] J. K. Preacher and A. F. Hayes, "SPSS and SAS procedures for estimating indirect effects in simple mediation models," Behavior Research Methods, Instruments, and Computers, vol. 36, no. 4, pp. 717-731, 2004.

[63] A. D. Vaus, Surveys in Social Research, 5th ed. Australia: Allen and Unwin, Crows Nest, pp. 379, 2002

[64] S. O'Leary and J. Deegan, "Ireland's Image as a Tourism Destination in France: Attribute Importance and Performance," Journal of Travel Research, vol. 43, pp. 247-256, 2005.

[65] V. Rajan, "Factors affecting tourist destination loyalty: A case study of Munnar, India as a tourism destination," presented at International Conference on Business, Economics and Management (ICBEM' 15), Phuket, Thailand, 2015.

[66] M. D. Harline and K. C. Jones, "Employee performance cues in a Hotels Service Environment: Influence on perceived service quality, value, and word-of-mouth intentions," Journal of Business Research, vol. 35, pp. 207-215, 1996

[67] M. K. Rahman, "Motivating factors of Islamic tourist's destination loyalty: A empirical investigation in Malaysia," Journal of Tourism and Hospitality Management, vol. 2, no. 1, pp. 63-77, June 2014

[68] A. Haque and A. H. Khan, "Factors influencing of tourist loyalty: A study on tourist destinations in Malaysia," in Proc. 3rd Asia-Pacific Business Research Conference, 25 - 26 February 2013, Kuala Lumpur, Malaysia, 2013.

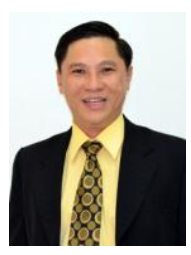

Mai Ngoc Khuong is a lecturer and researcher of School of Business Administration, International University, Vietnam National University- Ho Chi Minh City. He has bachelor degree in Tourism and Hospitality Management master of science degree in leisure, tourism and environment at Wageningen University, The Netherlands, and $\mathrm{PhD}$ degree in development management at School of Public Administration of the National Institute of Development Administration (NIDA), Bangkok-Thailand. 